\title{
Apple Sunburn Risk Detection-A Simple Model for Agricultural Decision Making and Some Fruit Temperature Measurements
}

\author{
Klaus-Peter Wittich ${ }^{1}$ \\ Received: 26 September 2020 / Accepted: 21 December 2020 / Published online: 4 February 2021 \\ (c) The Author(s) 2021
}

\begin{abstract}
As a response to strong radiative heating, the fruit temperature of apples may rise significantly above the air temperature. This may result in damage to the skin tissue and the epidermal and hypodermal cell layers. To avoid economic losses induced by sunburn symptoms on the skin, apple growers need forecasts of the fruit temperature, which will allow them to organize sun-protection measures in time.

The temperatures of detached apples, which had been exposed to incident radiation and wind, were measured in order to quantify the extent of fruit heating under the climate conditions of northern Germany. On average, the daily maximum skin temperatures measured on the sunlit south side of the fruit during selected sunny and warm days were about $7^{\circ} \mathrm{C}$ above the daily maximum air temperature. However, skin temperatures of more than $40^{\circ} \mathrm{C}$ (the predefined warning threshold) were rarely detected, indicating that sunburn is still an uncommon phenomenon in northern Germany. Maximum apple-core temperatures were on average $4{ }^{\circ} \mathrm{C}$ higher than the maximum temperatures of ambient air.

Based on energy balance principles, a simple model has been developed to predict the diurnal cycle of the sky- and ground-facing hemispherical apple temperatures. Focusing on fruit growers' needs, daily temperature maxima of the modeled sky-facing hemisphere were compared with skin temperatures measured on the sunlit south side, resulting in a mean absolute error (MAE) of $1.7^{\circ} \mathrm{C}$. Comparison between daily maxima of total sphere temperatures and apple core temperatures provided better correlations $\left(\mathrm{MAE}=0.8^{\circ} \mathrm{C}\right)$.
\end{abstract}

Keywords Apple (Malus domestica Borkh.) · Fruit temperature · Bulk model · Sunburn

\section{Abschätzung des Risikos von Apfelsonnenbrand - ein einfaches Entscheidungsmodell und einige Apfeltemperaturmessungen}

\section{Zusammenfassung}

Intensive Sonnenstrahlung kann die Fruchttemperatur von Äpfeln deutlich über die Lufttemperatur ansteigen lassen und zu Schäden an der Schale und den darunterliegenden Zellschichten führen. Um wirtschaftliche Verluste durch Sonnenbrandsymptome mittels rechtzeitig einzuleitender Schutzmaßnahmen zu vermeiden, sind Prognosen der Apfeltemperatur hilfreich.

Um für das Modell die Erwärmung von Äpfeln unter norddeutschen Klimabedingungen bei ungehinderter Sonneneinstrahlung und ungehindertem Windeinfluss zu quantifizieren, wurden mikroklimatische Messungen durchgeführt. Im Mittel lag das Tagesmaximum der Schale auf der nach Süden gerichteten Fläche um $7^{\circ} \mathrm{C}$ über dem täglichen Lufttemperaturmaximum. Schalentemperaturen von $40^{\circ} \mathrm{C}$ (als vordefinierte Warnschwelle) und darüber hinaus wurden nur selten erreicht, weshalb Sonnenbrand am Apfel ein eher noch ungewöhnliches Phänomen in Norddeutschland ist. Maximale Kerntemperaturen lagen im Mittel um $4^{\circ} \mathrm{C}$ höher als das Tagesmaximum der Lufttemperatur.

Klaus-Peter Wittich

klaus-peter.wittich@dwd.de
Zentrum für Agrarmeteorologische Forschung, Deutscher Wetterdienst (DWD), Bundesallee 33, 38116 Braunschweig, Germany 
Um die tagesperiodischen Temperaturen der dem Himmel und dem Boden zugewandten Apfelober- und -unterhälfte zu prognostizieren, wurde ein auf Energiebilanzprinzipien beruhendes Modell entwickelt. Der mittlere absolute Fehler zwischen den Tagesmaxima der modellierten Temperatur der Apfeloberhälfte und der gemessenen Schalentemperatur auf der sonnenbeschienenen Südseite lag bei $1,7^{\circ} \mathrm{C}$, während der mittlere absolute Fehler zwischen den Tagesmaxima der modellierten Gesamtfrucht- und gemessenen Kerntemperatur bei $0,8^{\circ} \mathrm{C}$ lag.

Schlüsselwörter Apfel (Malus domestica Borkh.) · Fruchttemperatur · Volumenmodell · Sonnenbrand

\section{Introduction}

During the last decade, fruit growers in Germany have become increasingly concerned about the growing apple yield losses caused by a physiological disorder of the fruit referred to as sunburn (Lebe and Schulte 2008; Steffens 2008, 2013; Wagner and Böttcher 2010; Wiebusch 2019). Apple sunburn is induced by excessive radiative heating of the fruits during the summer when the air temperature and light intensity are high and cooling wind is lacking. This environmental impact causes skin discolorations on the southwest facing side of the fruits, ranging from bleaching or yellowing through to browning and blackening (Schrader et al. 2001, 2003a). These pigment changes (see Fig. 1), which are partly associated with sub-surface cell damage, are classified into three different types of sunburn: Sunburn browning, which appears as a yellow to dark brown patch, is caused by skin temperatures over approx. $45^{\circ} \mathrm{C}$ and bright sunshine with high UV-B impact. Sunburn necrosis, which shows as a dark brown or black patch, is associated with (sub-)epidermal thermal death. It is caused exclusively by skin temperatures of over approx. $52^{\circ} \mathrm{C}$. The third type, photo-oxidative sunburn, however, is independent of any significant temperature trigger and therefore occurs at far below the skin-temperature thresholds mentioned. It is caused largely by irradiation leaving a bleached patch. This type of damage occurs when light exposure suddenly changes, i.e. when apples, which previously grew in shaded parts of the tree, abruptly experience intense sunlight after sheltering foliage is removed (Racskó and Schrader 2012). The sudden change from shade to direct sunlight may happen during excessive summer pruning.

Apple sunburn affects all important apple production regions in warm climates, where it leads to economic losses. In the Gouldburn Valley, northern Victoria, one of Australia's most important fruit producing regions, losses due to sunburn are estimated at between 6 and 50\%, depending on the variety and season (Lolicato 2011). In Washington State, the main apple-growing area in the United States (and also the world's largest one), where $50 \%$ of the US yield is produced, approximately $10 \%$ of the apples are damaged, resulting in mean financial losses of up to US $\$ 100 \mathrm{~m}$ per year (Racskó and Schrader 2012). High losses were also reported from unprotected orchards in Chile, Spain and Turkey (see citations in Racskó and Schrader 2012). In the Western Cape of South Africa, 20\% of harvested apples are downgraded due to sunburn (Makeredza 2011). Consequently, fruit growers are interested in receiving forecasts about when skin temperatures could reach a critical threshold, thus allowing them to take preventive measures.

According to observations made in Oregon, USA, apple sunburn has been known for more than 100 years (Racskó and Schrader 2012). In the German-speaking part of Europe, this type of fruit damage has been reported since the 1930s (Kobel 1931). However, few experimental and theoretical analyses have been conducted so far in Germany. Therefore, this paper presents a simple model, the results of which are compared with measurements conducted under summer and fall conditions.

At the international level, a number of authors have developed various predictive models of different complexity. For example, there are simple risk indicators based solely on thresholds of daily maximum air temperature (Holmes et al. 2009 (cited by Lolicato 2011), Darbyshire et al. 2015). Wagner and Böttcher (2010) proposed a 2parameter approach based on maximum air temperatures and the daily sum of global radiation, while Zhang and Schrader (Schrader 2010) used an empirical multi-parameter estimate: sunburn is likely to occur when average solar radiation is above $700 \mathrm{~W} \mathrm{~m}^{-2}$, average air temperature is above $30^{\circ} \mathrm{C}$, average relative humidity is lower than $26 \%$ and average wind speed is less than $3 \mathrm{mph}$ between 11 a.m. and 2 p.m. Taking account of the convective heat transfer between the skin and the ambient atmosphere, Thorpe (1974) calculated stationary temperature profiles in an apple for different angles of incident radiation. A similar model was developed by Smart and Sinclair (1976) for grapes and other spherical fruit. Li et al. (2014) focussed their calculations on the skin temperature of apples while disregarding fruit volume, and therefore thermal conductivity. Despite this simplification, their model exhibits a high degree of predictive accuracy. Saudreau et al. (2007) developed a complex 3-D model for dynamic and non-homogeneous intra-fruit conditions using a spherical mesh with 1000 grid points. Comparisons with measurements yielded excellent results, with small root mean square errors between 0.7 and $0.8^{\circ} \mathrm{C}$. 


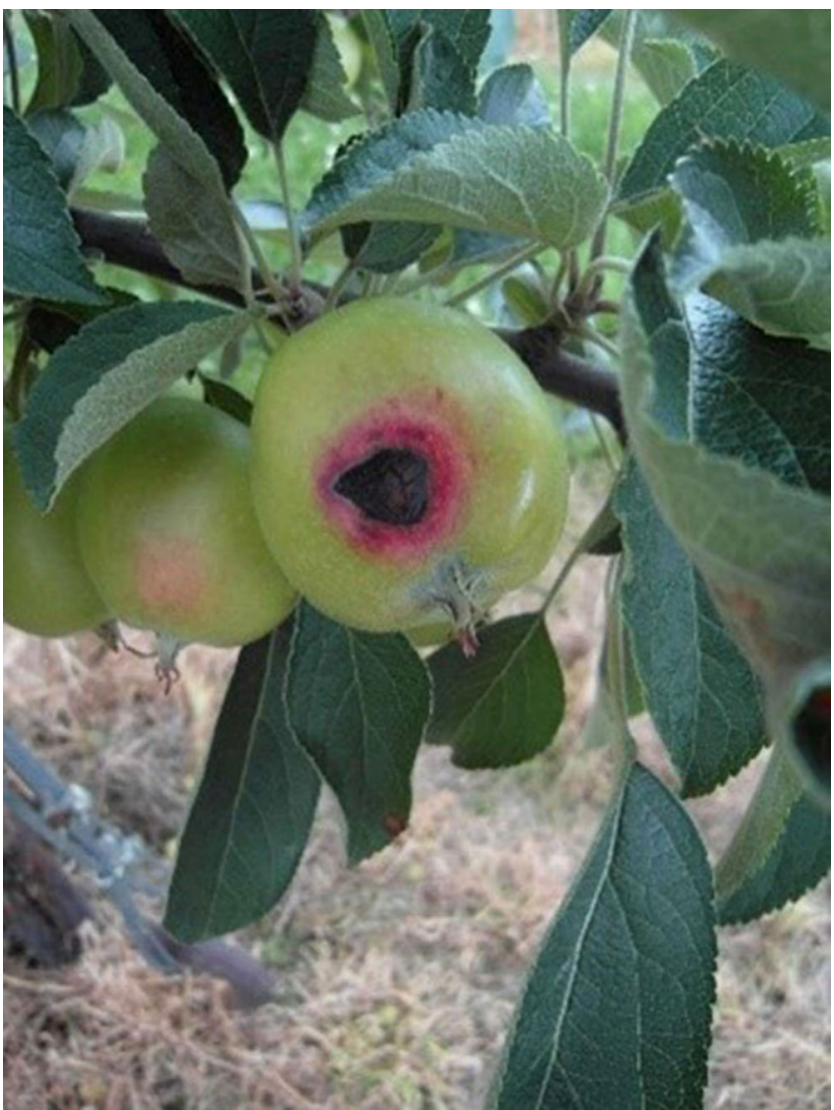

Fig. 1 Sunburn necrosis and browning of cv. 'Braeburn Hillwell' apples at Klein-Altendorf, Germany. (Courtesy of Dr M. Blanke, University of Bonn)

The next section presents a simple one-dimensional energy balance model for an idealized detached apple exposed to full irradiation and undisturbed flow conditions. Shadowing by canopy elements (leaves, twigs, etc.) and wetting by rain or dew are not considered. The model distinguishes between bulk temperatures of the two halves of the fruit: one half is facing the sky and the other is facing the vegetated ground. These view directions correspond to those of a net radiometer with an upper sensor dome receiving radiation from the sky and a lower one receiving radiation from the land surface. The question to be answered here is whether the model with its analogue sensor design is able to provide robust estimates of fruit temperatures.

\section{Materials and Methods}

\section{Modeling}

It is assumed that the apple has a spherical shape for which $A_{f}=\pi d_{f}^{2}$ the fruit surface, $V_{f}=\pi d_{f}^{3} / 6$ the fruit volume and $d_{f}$ $(=0.07 \mathrm{~m})$ the fruit diameter (subscript $f$ for fruit).
Solar radiation is absorbed by the fruit and converted to heat. Following the law of conservation of energy, the temperature of the fruit is affected by a number of energy fluxes $F_{i}$ (in $\mathrm{W}$ ) or flux densities $F_{d, i}$ (in $\mathrm{W} \mathrm{m}^{-2}$ ) according to:

$\rho_{f} c_{f} \frac{\partial T_{f}}{\partial t} V_{f}=\int_{A_{f}} F_{d, i} \partial A_{f}$

where $\varrho_{f}$ is the fruit density, $c_{f}$ the specific heat, $T_{f}$ the bulk temperature of fruit and $t$ the time. Fruit density is set at $900 \mathrm{~kg} \mathrm{~m}^{-3}$, which is within the range of $790-1200 \mathrm{~kg} \mathrm{~m}^{-3}$ specified by several authors (Häckel 1973; Sweat 1974; Saudreau et al. 2007).

The specific heat is given by $c_{f}=(1-w) c_{f, d r y}+w c_{w}$, with $w$ the fractional water content (wet basis), $c_{f, d r y}$ the specific heat of the dry mass of fruit $\left(1.21 \times 10^{3} \mathrm{~J} \mathrm{~kg}^{-1} \mathrm{~K}^{-1}\right)$ and $c_{w}$ the specific heat of water $\left(4.182 \times 10^{3} \mathrm{~J} \mathrm{~kg}^{-1} \mathrm{~K}^{-1}\right)$ (Tscheuschner 2004). With $w$ preset to 0.875 , which is between 0.849 and 0.885 mentioned by Sweat (1974) for red and green apples, the specific heat amounts to $3.810 \times 10^{3} \mathrm{~J} \mathrm{~kg}^{-1} \mathrm{~K}^{-1}$ (see also Häckel (1973) who found that $c_{f}=3.391 \times 10^{3} \mathrm{~J} \mathrm{~kg}^{-1} \mathrm{~K}^{-1}$ ).

The energy fluxes $F_{i}\left(=F_{d, i} * A\right)$ include the sensible heat flux within the boundary layer surrounding the fruit, $H$, the flux of net radiation, $R$, and the heat flux within the fruit, $G$. The transpirational flux is neglected (see also Saudreau et al. 2007) because the number and size of stomata on the fruit surface are very small (Blanke and Lenz 1985; Thorpe 1974). Therefore, the amount of fruit water is assumed to remain constant over time.

Subsequently, all fluxes will be related to the fruit hemispheres, i.e. to the upper hemisphere facing the sky and the lower hemisphere facing the ground or a leaf layer of the canopy. During daytime, the sunlit side is warmer than the opposite (i.e. shaded) side, and at night under cloudless conditions the sky-facing side may be cooler than that facing the ground. Consequently, a heat flux $(G)$ is established which compensates the temperature difference between the two hemispheres via heat conduction from the warmer to the cooler half according to:

$G_{\text {sky }}=2 k_{f}\left(T_{f, \text { sky }}-T_{f, \text { grd }}\right) A_{f, c s} / d_{f}$

$G_{\text {grd }}=-G_{\text {sky }}$

with $T_{f, s k y}$ and $T_{f, g r d}$ the fruit temperatures (in K) of the upper half interacting with the sky and the lower half in energy exchange with the foliated canopy layer below, or the ground (subscripts $s k y$ and $g r d$, respectively), $A_{f, c s}=A_{f} / 4$ the circular cross-sectional area touching the apple core, and $k_{f}$ the thermal conductivity of the fruit preset to $0.49 \mathrm{~W} \mathrm{~m}^{-1} \mathrm{~K}^{-1}$, i.e. within the parameter range defined by Häckel (1973), Sweat (1974), Donsì et al. (1996), and Lisowa et al. (2002). 


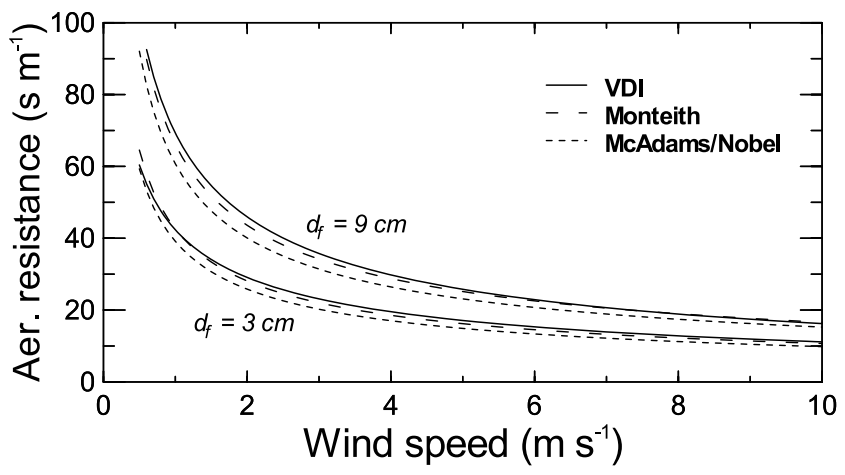

Fig. 2 Comparison of three aerodynamic resistance formulas for forced convection in boundary layer flows about spheres of 3 and $9 \mathrm{~cm}$ in diameter

Equation 2 reveals that the amount of heat lost by one of the hemispheres is gained by the other, and vice versa.

Net radiation is given by:

$$
\begin{aligned}
& R_{\text {sky }}=\left(S_{\downarrow}\left(1-\alpha_{f}\right)+L_{\downarrow}-\varepsilon_{f} \sigma T_{f, \text { sky }}^{4}\right) A_{f, \text { sky }} \\
& R_{\text {grd }}=\left(S_{\downarrow} \alpha_{\text {can }}\left(1-\alpha_{f}\right)+\varepsilon_{\text {can }} \sigma T_{\text {can }}^{4}-\varepsilon_{f} \sigma T_{f, \text { grd }}^{4}\right) A_{f, \text { grd }}
\end{aligned}
$$

with $A_{f, s k y}=A_{f, g r d}=A_{f} / 2, S_{\downarrow}$ the downward directed shortwave (global) radiation (in $\left.\mathrm{W} \mathrm{m}^{-2}\right), \alpha_{f}(=0.55)$ and $\alpha_{\text {can }}(=0.22)$ the fruit and canopy albedo (subscript can), $L_{\downarrow}$ the longwave (thermal) sky radiation (in $\mathrm{W} \mathrm{m}^{-2}$ ), $\varepsilon_{f}$ and $\varepsilon_{\text {can }}$ the thermal emissivity of fruit $(=0.95)$ and canopy $(=0.98)$, and $\sigma$ the Stefan-Boltzmann constant $\left(=5.67 \times 10^{-8} \mathrm{~W} \mathrm{~m}^{-2} \mathrm{~K}^{-4}\right)$. Note that Thorpe (1974), Evans (2004) and Li et al. (2014) used fruit albedos of 0.3 and 0.6 for their model calculations. In general, $\alpha_{f}$ depends on fruit properties such as fruit color, geometric parameters (e.g. angle of incident sunlight, view direction of sensor), and the spectral range of the sensor. According to Blanke (1989), $\alpha_{f}$ is in the range between 0.1 and 0.8 .

The canopy albedo used in our model is similar to that of Landsberg et al. (1973), who found 0.22-0.19 for May to July conditions in the west of England. The fruit emissivity is within the range $0.94-0.97$ reported by Hellebrand et al. (2001), while the canopy emissivity is between 0.95 and 1.0 as used by Butler (1976) and Green and McNaughton (1997). The unknown canopy temperature, $T_{\text {can }}$, is approximated by air temperature because widelyspaced tree rows allows adequate ventilation.

The heat exchange between the fruit and its ambient air is calculated via the sensible heat flux describing the heat loss through forced convection during daytime and heat gain during the nighttime according to:

$H_{\mathrm{sky}}=-\rho_{a} c_{p}\left(T_{a}-T_{f, \mathrm{sky}}\right) A_{f, \mathrm{sky}} / r_{h}$
$H_{\mathrm{grd}}=-\rho_{a} c_{p}\left(T_{a}-T_{f, \mathrm{grd}}\right) A_{f, \mathrm{grd}} / r_{h}$

with $\varrho_{a}$ the air density $\left(\approx 1.2 \mathrm{~kg} \mathrm{~m}^{-3}\right.$, subscript $a$ for air) and $c_{p}$ the specific heat of air at constant pressure ( $\approx 1005 \mathrm{~J} \mathrm{~kg}^{-1} \mathrm{~K}^{-1}$ ), and $T_{a}$, the air temperature. The parameter $r_{h}$ describes the resistance to the heat transfer between the fruit and surrounding air according to:

$r_{h}=\frac{1}{N u} \frac{d_{f}}{D_{h}}$

with $\mathrm{Nu}$ the uniform Nusselt number and $D_{h}$ the coefficient of diffusivity for heat (e.g., $D_{h}=2.11 \times 10^{-5} \mathrm{~m}^{2} \mathrm{~s}^{-1}$ at $20^{\circ} \mathrm{C}$ ). It is assumed that flow conditions can be characterized by forced convection (Smart and Sinclair 1976; Saudreau et al. 2007). According to VDI (2006), the formula:

$N u=2.0+\left(N u_{\text {lam }}^{2}+N u_{\text {turb }}^{2}\right)^{1 / 2}$

can be used with:

$N u_{\text {lam }}=0.664 \operatorname{Re}^{1 / 2} \operatorname{Pr}^{1 / 3}$

and:

$$
\begin{aligned}
N u_{\text {turb }}= & \left(0.037 R e^{0.8} P r\right) / \\
& \left(1.0+2.443 \operatorname{Re}^{-0.1}\left\{P r^{2 / 3}-1.0\right\}\right)
\end{aligned}
$$

for laminar and turbulent flows. Here, $R e=u_{a} d_{f} / v_{a}$ and $\operatorname{Pr}=v_{a} / D_{h}$ are the Reynolds and Prandtl number, respectively, with $u_{a}$ the wind speed (in $\mathrm{m} \mathrm{s}^{-1}$ ) measured at crown level $(\sim 2 \mathrm{~m})$ and $v_{a}$ the kinematic viscosity of air (e.g., $v_{a}=1.51 \times 10^{-5} \mathrm{~m}^{2} \mathrm{~s}^{-1}$ at $\left.20^{\circ} \mathrm{C}\right)$. An alternative approximation for spherical objects is:

$N u=a * R e^{0.6}$

with $a=0.37$ mentioned by McAdams (1954) and Nobel (1975), and $a=0.34$ according to Monteith and Unsworth (2013), see Fig. 2 and further comments in the Discussion section.

In order to obtain the fruit temperatures, Eqs. 2-4 have to be substituted into the heat-budget equations for the skyand ground-facing hemispheres given by:

$\rho_{f} c_{f} \frac{\partial T_{f, \text { sky }}}{\partial t} V_{f, \text { sky }}=R_{\text {sky }}-G_{\text {sky }}-H_{\text {sky }}$

$\rho_{f} c_{f} \frac{\partial T_{f, \mathrm{grd}}}{\partial t} V_{f, \mathrm{grd}}=R_{\mathrm{grd}}-G_{\mathrm{grd}}-H_{\mathrm{grd}}$

Eqs. $7 \mathrm{a}$ and $7 \mathrm{~b}$ are merged to provide the total fruit temperature, $T_{f}$, thus leading to the heat-budget formula:

$\rho_{f} c_{f} \frac{\partial T_{f}}{\partial t} V_{f}=R-H$ 
with $V_{f}=V_{f, s k y}+V_{f, g r d}$. The fluxes on the r.h.s. of Eq. 8a are given by:

$H=H_{\mathrm{sky}}+H_{\mathrm{grd}}=-\rho_{a} c_{p}\left(T_{a}-T_{f}\right) A_{f} / r_{h}$

and:

$$
\begin{aligned}
& R=R_{\text {sky }}+R_{\text {grd }}= \\
& \left\{\frac{S_{\downarrow}\left(1-\alpha_{f}\right)\left[1+\alpha_{\mathrm{can}}\right]}{2}+\frac{L_{\downarrow}+\varepsilon_{\mathrm{can}} \sigma T_{\mathrm{can}}^{4}}{2}-\varepsilon_{f} \sigma T_{f}^{4}\right\} \\
& \times A_{f}
\end{aligned}
$$

with $T_{f}=\left(T_{f, s k y}+T_{f, g r d}\right) / 2$ and $T_{f}^{4}=\left(T_{f, s k y}{ }^{4}+T_{f, g r d}{ }^{4}\right) / 2$ when the linearization $T_{f}^{4}=T_{a}^{4}-4 T_{a}^{3}\left(T_{a}-T_{f}\right)$ is taken into account.

In operational mode, the model is supplied with hourly data $\left(T_{a}, u_{a}, S_{\downarrow}, L_{\downarrow}\right)$ taken from open-field weather stations and the DWD's numerical weather prediction model. The time step of $\Delta t=1 \mathrm{hr}$, however, is too large for numerical integration of Eqs. 7 and 8 due to finite differences resulting in numerical instability for small sphere diameters. Therefore, obeying the CFL (Courant-Friedrichs-Lewy) convergence criterion, we use internal time steps of $\Delta t=360 \mathrm{~s}$ which are 10-times smaller. The uppermost $\Delta t$ allowed by CFL is $\Delta t_{\max }=\left(d_{f} / 2\right)^{2} /\left(2 \times a_{f}\right)$ with $a_{f}=k_{f} /\left(\varrho_{f} c_{f}\right)$ the fruit's diffusion coefficient $\left(a_{f} \approx 0.143 \times 10^{-6} \mathrm{~m}^{2} \mathrm{~s}^{-1}\right)$, resulting in $\Delta t_{\max }$ $\sim 350-4280 \mathrm{~s}$ for $d_{f}$ between 2 and $7 \mathrm{~cm}$.

\section{Measurements}

A simple field experiment was performed in the climate garden of DWD's Agrometeorological Research Centre in Braunschweig, northern Germany $\left(\lambda=10^{\circ} 26.55^{\prime} \mathrm{E}, \phi=52^{\circ}\right.$ $\left.17.35^{\prime} \mathrm{N}, h=81 \mathrm{~m}\right)$. The station is part of the official synoptic network, which means that measurements taken there meet the standards of the World Meteorological Organization (WMO 2014).

A detached apple was fully exposed to a free air stream and solar radiation by mounting it between two horizontal metal rods approx. $1.7 \mathrm{~m}$ above grass (Fig. $7 \mathrm{~b}$ ). The fruit temperature was measured using platinum resistance thermometers (PT 100) placed at two different positions: one PT element was inserted into the core of the apple and the other one was installed in the front third between the southfacing fruit surface and the fruit's center. The measurement precision was $\pm 0.1 \mathrm{~K}$.

In parallel, the skin temperature on the south-facing side of the fruit was sensed using an infrared radiation pyrometer (KT 19, Heitronics, Wiesbaden, Germany). In the 8-14 $\mu$ m window, it receives longwave radiation emitted by the apple. The measuring signal was converted to the surface temperature with an accuracy of measurement of (better than) $\pm 1 \mathrm{~K}$. The view axis of the pyrometer was from south to north, hitting the south-facing side near its center, slightly above the apple's equator. Given the pyrometer's measuring distance and scan parameters, the measuring spot covered a circular patch of skin of approx. $2 \mathrm{~cm}$ in diameter. The central measuring position was selected to avoid the target point drifting out of the sensor's field of view under stronger wind movement. In certain additional campaigns a second KT-pyrometer was positioned north of the apple, facing south. The measuring spot was a little below the apple's equator so that the visual axis between the two KTs was directed slightly downward from $\mathrm{S}$ to $\mathrm{N}$.

In a few cases, thermal images were taken for validation purposes using infrared thermometry to capture the skintemperature distribution in high spatial resolution. The camera used for these measurements was an imaging VarioCam hr research 600 thermography camera (InfraTec, Dresden, Germany; resolution: $640 \times 480$ pixels). It was installed next to the southern KT pyrometer, thus taking on a slightly different view direction. Snapshots of skin temperatures from the whole south-facing surface of the apple were provided every $15 \mathrm{~min}$ with a relative measuring error of $\pm 0.1 \mathrm{~K}$ and an absolute measuring error of $\pm 1.5 \mathrm{~K}$. Note that, according to Hellebrand et al. (2001), reliable data can only be expected from those parts of the spherical surface which are oriented nearly perpendicular to the sensor view angle. Therefore, thermometry of the outer region of the apple is less reliable.

\section{Results}

\section{Model Behavior}

This section analyzes the responses of total fruit temperature, $T_{f}$, to stationary atmospheric forcing and a spontaneous step change in environmental conditions.

Steady-state conditions occur as soon as the fluxes between fruit and atmosphere balance out and reach equilibrium. The equilibrium (subscript $e q$ ) fruit temperature reads:

$$
\begin{aligned}
& T_{f, e q}=T_{a}+ \\
& \left\{\frac{S_{\downarrow}\left(1-\alpha_{f}\right)\left[1+\alpha_{\mathrm{can}}\right]}{2}+\frac{L_{\downarrow}+\varepsilon_{\mathrm{can}} \sigma T_{\mathrm{can}}^{4}}{2}-\varepsilon_{f} \sigma T_{a}^{4}\right\} / \\
& \left\{4 \varepsilon_{f} \sigma T_{a}^{3}+\rho_{a} c_{p} / r_{h}\right\}
\end{aligned}
$$

For a test run in the $T_{f, e q}=f\left(u_{a}\right)$ space, the fruit diameter $d_{f}$ is set at $7 \mathrm{~cm}$, air and canopy temperature at $T_{a}=T_{\text {can }}=30^{\circ} \mathrm{C}$ $(303.15 \mathrm{~K})$, and thermal sky radiation at $L_{\downarrow}=350 \mathrm{~W} \mathrm{~m} \mathrm{~m}^{-2}$, whereas irradiation is set to $S_{\downarrow}=300,500,900 \mathrm{~W} \mathrm{~m}^{-2}$. Each of the three gray areas in Fig. 3a is described by a discrete 



Fig. 3 Equilibrium fruit temperature as a function of wind speed for different global radiation and albedo values (a). The gray areas are based on $S_{\downarrow}=300,500$ and $900 \mathrm{~W} \mathrm{~m}^{-2}$ with upper and lower bounds given by $\alpha_{f}=0.25$ and 0.5 , respectively (sphere diameter set at $7 \mathrm{~cm}$; all other parameters are given in the text). b Equilibrium fruit temperature as a function of global radiation for albedo values of 0.25 (upper gray area) and 0.5 (lower gray area); lower and upper boundaries are defined by sphere diameters of 3 and $9 \mathrm{~cm}$, respectively. Wind speed is set at $1 \mathrm{~m} \mathrm{~s}^{-1}$. $\mathbf{c}$ Timelag as a function of wind speed for different fruit diameters

$S_{\downarrow}$ value and albedo values of $\alpha_{f}=0.25$ (upper boundary) and 0.5 (lower boundary). All other parameters are given in the Modeling Section above. As can be seen in Fig. 3a, increasing wind speeds lead to rising heat losses and declining fruit temperatures as a consequence of enhanced turbulent mixing via forced convection. The $T_{f, e q}\left(u_{a}\right)$ relationship is non-linear, which is consistent with the modeling results of Thorpe (1974, his Fig. 3b) and Smart and Sinclair (1976, their Fig. 4). Increasing global radiation results in greater heat absorption and therefore increasing total fruit temperature. For example, in the sample space defined by $u_{a}=1 \mathrm{~m} \mathrm{~s}^{-1}, S_{\downarrow}=500 \mathrm{~W} \mathrm{~m}^{-2}$ and $\alpha_{f}$ in the range between 0.5 and $0.25, T_{f, e q}$ deviates from the air temperature by +4.4 to $7.5^{\circ} \mathrm{C}$. If $S_{\downarrow}$ increases to $900 \mathrm{~W} \mathrm{~m}^{-2}, T_{f, e q}$ exceeds $T_{a}$ by 9.3 to $14.9^{\circ} \mathrm{C}$ depending on the two albedo values given.

Fig. $3 \mathrm{~b}$ shows the effect of fruit dimension and albedo on equilibrium fruit temperature in the $T_{f, e q}=\mathrm{f}\left(S_{\downarrow}\right)$ space. Wind speed is set at $1 \mathrm{~m} \mathrm{~s}^{-1}$ in order to minimize wind-induced convective cooling under irradiance conditions. Model runs are made for the two albedo values of 0.25 and 0.5 , each combined with fruit diameters of $d_{f}=3$ (lower limit of graycolored areas in Fig. 3b) and $9 \mathrm{~cm}$ (upper limit). The dependency of $T_{f, e q}$ on $S_{\downarrow}$ is linear, with the largest exceedance of ambient air temperature $\left(30^{\circ} \mathrm{C}\right)$ at high irradiance and low fruit albedo. Larger fruits are warmer than smaller ones for irradiances above low-light thresholds of $148 \mathrm{~W} \mathrm{~m}^{-2}$ (the $\alpha_{f}=0.5$ case) and $100 \mathrm{~W} \mathrm{~m}^{-2}$ (the $\alpha_{f}=0.25$ case). One reason for this behavior is that the aerodynamic resistance is greater for larger spheres than for smaller ones (see Fig. 2). Therefore, the greater the fruit diameter, the weaker the heat exchange with the ambient air. Below the low-light threshold, the fruits become cooler than the air. At total darkness, i.e. $S_{\downarrow}=0 \mathrm{~W} \mathrm{~m}{ }^{-2}$, the fruit temperature falls below the air temperature by up to $4{ }^{\circ} \mathrm{C}$ depending on $d_{f}$ (not shown, visual extrapolation of lines into the range $T_{f, e q}<30^{\circ} \mathrm{C}$ ). Note that the equilibrium solution given by Eq. 9 becomes independent of $u_{a}$ and $d_{f}$ if $T_{f, e q}$ reaches air temperature, so that $\alpha_{f}$-specific $T_{f, e q}\left(S_{\downarrow}\right)$ profiles have a common intersection point on the abscissa in Fig. $3 b$.

In order to show the effect of a step change in irradiance which occurs, for example, during summer pruning when the fruit suffers an abrupt increase of light intensity, $T_{f}$ responds with a rapid (exponential) increase from its initial value $T_{f}\left(t_{0}\right)$ to the new (final) steady-state value, $T_{f, e q}$. The analytical solution of Eq. 8a yields:

$\frac{T_{f}(t)-T_{f, e q}}{T_{f}\left(t_{0}\right)-T_{f, e q}}=\exp (-t / \tau)$

with $T_{f, e q}$ described by Eq. 9 and the timelag parameter, $\tau$ (in s), given by:

$\tau=\frac{\rho_{f} c_{f} d_{f} / 6}{4 \varepsilon_{f} \sigma T_{a}^{3}+\rho_{a} c_{p} / r_{h}}$

The higher the wind speed or turbulent heat transfer and the smaller the fruit diameter, the shorter the timelag, and the faster the fruit temperature attains its new equilibrium value (Fig. 3c). Therefore, when subjected to a warm-air environment, small apples are able to heat up more quickly than bigger ones, especially under windy and turbulent conditions. 
a

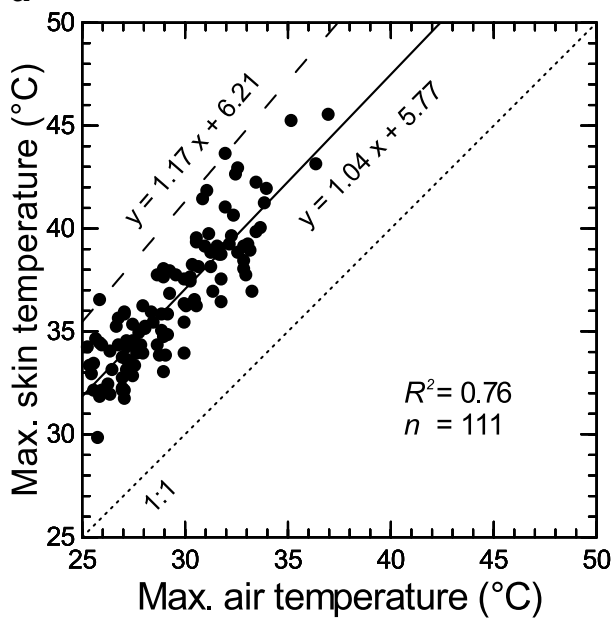

b

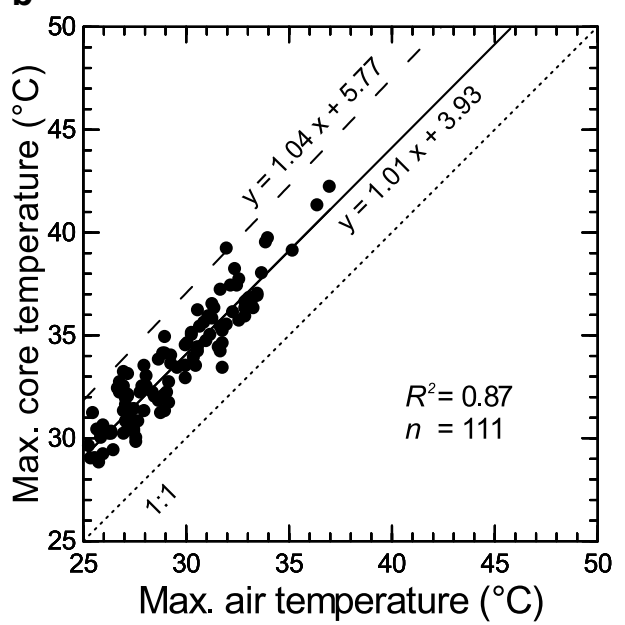

Fig. 4 a Daily maximum KT skin temperature (south-facing side), $T_{s, \max }$, versus daily maximum air temperature, $T_{a, \max }$, on $n=111$ days when $T_{a, \max }$ was above $25^{\circ} \mathrm{C}$. The solid line is applied to the data record by linear regression. The dashed line in the upper left of the figure reflects the conditions found in Washington State (taken from Schrader et al. 2003b). b As Fig. 3a, but for daily maximum PT core temperature vs. maximum air temperature. For reasons of comparison, the $T_{c, \max }=\mathrm{f}\left(T_{a, \max }\right)$ regression line (solid curve) is plotted together with the $T_{s, \max }=\mathrm{f}\left(T_{a, \max }\right)$ line adopted from Fig. 3a (dashed curve drawn at the upper margin of the data pool)

\section{Measurements and Model Verification}

As expected, on fair summer and fall days the surface temperature of the sunlit south-facing side of the apple becomes much hotter than the ambient air because of strong heat absorption in the fruit. In Fig. 4a the daily maximum KT-19 skin temperature is plotted against the daily maximum air temperature, both taken from the respective diurnal time series of 111 days. The data pool used comprises those days of measuring campaigns when $T_{a, \max }$ exceeded $25^{\circ} \mathrm{C}$. Maximum skin temperature, $T_{s, \text { max }}$, exceeds maximum air temperature by about $7{ }^{\circ} \mathrm{C}$. As the radiation temperature measured by the KT sensor on the fruit surface is directly affected by fluctuating wind speeds and occasional shadows thrown by passing clouds, the observed scatter of data is relatively large as proved by the moderate value of the coefficient of determination, $R^{2}=0.76$ (i.e. $76 \%$ of the total variance of $T_{s, \max }$ can be explained by $T_{a, \max }$ ). Linear regression between both data sets provides $T_{s, \max }=1.04 \times T_{a, \max }+5.77$ (with $T$ expressed in ${ }^{\circ} \mathrm{C}$, solid line). Fig. $4 \mathrm{a}$ also incorporates the results reported by Schrader et al. (2003b) for Washington State (USA). They found $T_{s, \max }=1.17 \times T_{a, \max }+6.21$ (with $T$ in ${ }^{\circ} \mathrm{C}$, dashed line). Braunschweig data are below this reference line, indicating that the climate conditions in northern Germany are less severe than those found in Washington State. Therefore, it is not surprising that sunburn events are less common in Germany.

Fig. $4 \mathrm{~b}$ compares the daily maxima of apple-core temperatures, $T_{c, \max }$, with those of ambient air, $T_{a, \max }$. The regression line, $T_{c, \max }=1.01 \times T_{a, \max }+3.93$ (with $T$ in ${ }^{\circ} \mathrm{C}$, solid line), has nearly the same slope as the $T_{s, \max }=\mathrm{f}\left(T_{a, \max }\right)$ line adopted from Fig. 4a and reproduced in Fig. $4 \mathrm{~b}$ as a dashed line.
But the offset between $T_{c, \max }$ and $T_{a, \max }$ is smaller $\left(4.1^{\circ} \mathrm{C}\right)$ because the temperature wave within the apple fruit is attenuated on its way from the south-facing skin towards the core (see the different amplitudes in Fig. 5b). Consequently, there is less scattering of data and the coefficient of determination is higher $\left(R^{2}=0.87\right)$ than in the $T_{s, \max }=\mathrm{f}\left(T_{a, \max }\right)$ data set plotted in Fig. 4 a.

To illustrate the time patterns of sunburn-related forcing and response parameters, Fig. 5a illustrates the diurnal cycle of impact parameter $S_{\downarrow}$ while Fig. 5b shows the forcing ambient air temperature together with the measured skin, pulp and core temperatures during the period 3-8 August 2018. While global radiation peaked around $800-900 \mathrm{~W} \mathrm{~m}^{-2}$ around noon, the daily maximum air temperatures varied between 25 and $37^{\circ} \mathrm{C}$. Maximum skin temperatures on the southern side of the apple were in the range of $33-43^{\circ} \mathrm{C}$, i.e. approx. $7^{\circ} \mathrm{C}$ above air temperature. On the opposite northern side below the equator, the maximum skin temperature was between 28 and $39^{\circ} \mathrm{C}$, i.e. about $5^{\circ} \mathrm{C}$ lower than on the opposite sunlit side, but approx. $3^{\circ} \mathrm{C}$ above the maximum air temperature. Under low-light conditions and during nighttime, the apple skin temperatures were close to or slightly below the air temperature (up to $3{ }^{\circ} \mathrm{C}$ ) without any pronounced intra-fruit temperature gradient (Fig. 5b). An unexpected development occurred on 5th of August: although global radiation peaked on this particular day of the measuring period, both the air and apple temperatures fell to their lowest level. This time pattern illustrates that air temperature is the key driver of fruit temperature while global radiation is a secondary impetus responsible for a heat surplus within certain energetic bounds. 

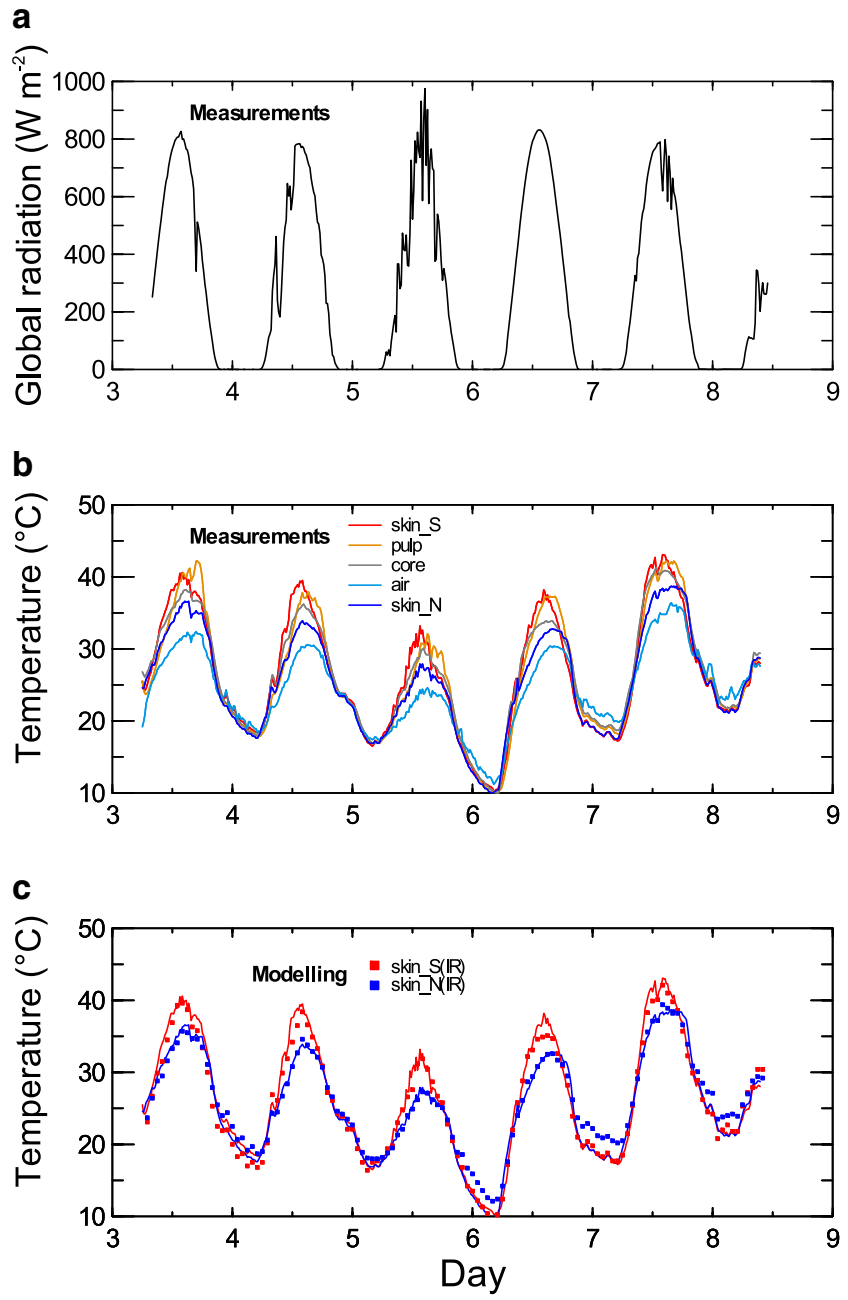

Fig. 5 Daily cycle of measured global radiation (a), air and fruit temperatures (b), and comparison with model simulation (measurements are plotted as solid curves and modeled values as dots) (c). Measuring site and date: Braunschweig, 3-8 August 2018

The modeled sky-facing bulk temperature and the measured skin temperature (south side) reveal similar diurnal variations (Fig. 5c). Note that the model runs used in Figs. 5 and 6 were initialized in mid-May each year (as in the routine runs), accordingly the model values did not perfectly reflect the starting values of the individual experiments.

When comparing KT's daily maximum spot temperatures measured on the sunlit skin near the equator, $T_{s, \max }$, with the modeled maximum sky-facing (upper-half) fruit temperatures, $T_{f, s k y, \max }$, we have to keep in mind that both variables refer to different (i.e. 2- and 3-dimensional) domains, i.e. modeled volumetric bulk values cannot precisely reflect local spot measurements on the skin. Fig. 6 shows that most modeled daily maximum skin temperatures are in the range $T_{f, s y, \text { max }}=T_{s, \text { max }} \pm 3{ }^{\circ} \mathrm{C}$.

In order to evaluate the model efficiency, we employ several performance measures, i.e. the mean bias error, $M B E$, the mean absolute error, $M A E$, the root mean square error, RMSE (with $M B E \leq M A E \leq R M S E$ ), the coefficient of determination, $R^{2}$, and the coefficient of efficiency, $E$ (see Table 1 for details). The coefficient of efficiency suggested by Nash and Sutcliffe (1970) and modified by Legates and McCabe (1999) is defined as:

$E=1-\frac{\sum_{i}^{n}\left|o_{i}-c_{i}\right|}{\sum_{i}^{n}\left|o_{i}-o_{a v}\right|}$

with $o_{i}$ the observed variable, $o_{a v}$ its average, and $c_{i}$ the computed value. The coefficient of efficiency is in the range $-\infty<E \leq 1$ where the upper bound represents the perfect fit. In the range $0 \leq E \leq 1$ the model provides reliable results, whereas in the negative range of $E$ the observed mean value is a better predictor than the model-simulated value, suggesting a revision of the model assumptions. Note that, in order to avoid an overvalued (i.e. excessive) rating score, the absolute terms in the modified version above replace the squared ones used in the original formula of Nash and Sutcliffe (1970).

Evaluating the model performance by setting $o_{i}=T_{s, \max }$ and $c_{i}=T_{f, s k y \text {, } m a x}$ provides correlation-based measures $\left(R^{2}\right.$ and $E$ ) of approx. 0.5, while the dimensioned statistics (MBE, MAE, RMSE) are in the range $0.9-2.3^{\circ} \mathrm{C}$, with $M A E\left(=1.7^{\circ} \mathrm{C}\right)$ the most natural measure of average error magnitude (Willmott and Matsuura 2005).

A similar model evaluation is performed for the daily maxima of measured core temperatures, $T_{c, \max }$, and calculated total fruit temperatures, $T_{f, \max }$ (merged with the two hemispherical volume temperatures to represent the total heat content of the fruit, i.e., $\left.T_{f, \text { max }}=\left(T_{f, s k y}+T_{f, g r d}\right)_{\max } / 2\right)$. The scatterplot in Fig. $6 \mathrm{~b}$ shows that most data pairs group along the 1:1 line. Apple-core related model performance is better than the skin-related one, as expected (see Table 1).

\section{Discussion}

\section{Measurements}

Our measurements on the south side of the apple show that, on average, daily maximum skin temperatures exceed the corresponding air temperatures by about $7{ }^{\circ} \mathrm{C}$ (Fig. 4). In extreme cases, e.g. during summer heat waves with air temperatures above $30^{\circ} \mathrm{C}$, skin temperatures rose to more than $40^{\circ} \mathrm{C}$ (Fig. 5). Temperature gradients between the sunlit and the shaded (opposite) side of the fruit surface were up to $6{ }^{\circ} \mathrm{C}$ around noon. At night, however, radiative cooling caused the sky-and ground-facing skin temperature to fall slightly below the air temperature while the intra-fruit temperature distribution became nearly isotropic. This is consistent with field measurements made in France and 
Fig. 6 Comparison of modeled and measured daily maximum fruit temperatures: a KT-skin temperature (spot pyrometer reading on the south side of the apple) vs. sky-facing fruit temperature (modeled hemisphere), b Measured core temperature (PT) vs. calculated total fruit temperature


Table 1 Model performance measures used in this study

\begin{tabular}{lll}
\hline Performance measure & South-facing skin vs. upper hemisphere & Core vs. total fruit \\
\hline Mean Bias Error: $M B E=n^{-1} \sum\left(o_{i}-c_{i}\right)$ & $0.88^{\circ} \mathrm{C}$ & $-0.26^{\circ} \mathrm{C}$ \\
Mean Absolute Error: $M A E=n^{-1} \sum o_{i}-c_{i} \mid$ & $1.71{ }^{\circ} \mathrm{C}$ & $0.82^{\circ} \mathrm{C}$ \\
Root Mean Square Error: $R M S E=\left\{n^{-1} \sum\left(o_{i}-c_{i}\right)^{2}\right\}^{0.5}$ & $2.25^{\circ} \mathrm{C}$ & $1.04{ }^{\circ} \mathrm{C}$ \\
Coefficient of determination: & & 0.88 \\
$R^{2}=\left[\sum\left\{\left(o_{i}-o_{a v}\right) \times\left(c_{i}-c_{a v}\right)\right\}\right]^{2} /\left\{\sum\left(o_{i}-o_{a v}\right)^{2} \times \Sigma\left(c_{i}-c_{a v}\right)^{2}\right\}$ & 0.61 & 0.65 \\
Modified Coefficient of Efficiency: $E($ see Eq. 11$)$ & 0.35 & \\
\hline
\end{tabular}

$o_{i}$ observations (south-facing skin, core), $c_{i}$ computed estimates (upper hemisphere, total fruit), $n$ number of data pairs

Switzerland by Saudreau et al. (2007, 2009) who found temperature deviations of $5-7^{\circ} \mathrm{C}$ between the apple skin and the surrounding air at noon, and up to $1{ }^{\circ} \mathrm{C}$ at nighttime. In the UK, field experimental work by Thorpe (1974) yielded hot-spot excess temperatures of up to $14^{\circ} \mathrm{C}$ under full sunlight $\left(630 \mathrm{~W} \mathrm{~m}^{-2}\right)$ while the opposite side was $3{ }^{\circ} \mathrm{C}$ warmer than the air. In the United States similar results were obtained by Brooks and Fisher (1926). According to the findings of Schrader et al. (2003b), plotted as a dashed line in Fig. 4a, the sunlit fruit surface was up to $12^{\circ} \mathrm{C}$ hotter than the ambient air temperature. In Australia, McCaskill et al. (2016) detected excess temperatures of up to $17^{\circ} \mathrm{C}$. Such extreme differences, however, were never observed during our measurement periods. It should be noted, however, that our data do not reflect the hot-spot conditions at or nearby the anti-solar point. In fact, our data mirror the slightly cooler region near the apple's sky-ground equator (temperature deviation up to $1-2{ }^{\circ} \mathrm{C}$ according to thermal images taken by infrared thermometry; see Fig. 7a).

\section{Model Results}

Our analytical concept modeling (Eq. 9, Fig. 3), which provides the steady-state equilibrium temperature for the total fruit volume under stationary forcing, shows similar outcomes to the fruit-skin related wind tunnel measure- ments by Thorpe (1974) and the open field experiments by Schrader et al. (2003b). The authors found that the effect of absorbed radiation and wind-induced convective heat loss are important for the degree of fruit-temperature rise above air temperature. For example, Thorpe (1974) illuminated apples at $500 \mathrm{~W} \mathrm{~m}^{-2}\left(\alpha_{f}=0.3, d_{f}=6 \mathrm{~cm}\right)$ and found that, on the side exposed to light, the equilibrium surface temperature rises to $6^{\circ} \mathrm{C}$ above air temperature at a wind speed of $4 \mathrm{~m} \mathrm{~s}^{-1}$, and to $11^{\circ} \mathrm{C}$ at a wind speed of $0.3 \mathrm{~m} \mathrm{~s}^{-1}$. The experiment by Schrader et al. (2003b) resulted in a negative correlation between $T_{s}$ (daily maximum) and $u_{a}$ (averaged between 11 a.m. and 5 p.m.). According to their linear regression equation, the maximum skin temperature increases by $5^{\circ} \mathrm{C}$ when the wind speed decreases from $3.5-0.5 \mathrm{~m} \mathrm{~s}^{-1}$. Our model provides an increase in total fruit equilibrium temperature by $2-3.5^{\circ} \mathrm{C}$ for $\alpha_{f}$ between 0.2 and 0.25 when the wind speed decreases from $4-1 \mathrm{~m} \mathrm{~s}^{-1}$ at a global radiation of $500 \mathrm{~W} \mathrm{~m}^{-2}$ (Fig. 3a). Under the same irradiance and wind conditions, the heat excess of fruit is $4-7.5^{\circ} \mathrm{C}$ above air temperature for the $\alpha_{f}$ range given. As expected, but in contrast to measurements taken by Thorpe (1974) and Schrader et al. (2003b) on the fruit surface which is subjected to the immediate energy exchange with the ambient air, our concept model shows smaller heat excess values due to its volumetric focus. 

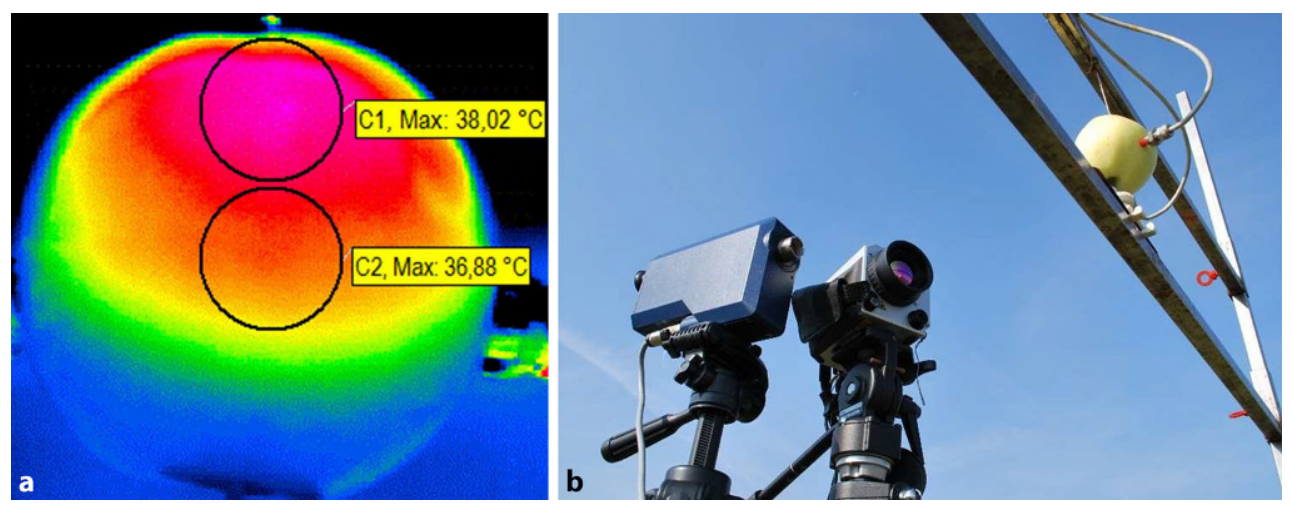

Fig. 7 a Thermographic image of the south-facing side of an apple measured with VarioCam, 18 July 2014, 12:35 CET (CET=Central European Time). Maximum skin temperature of the upper part of the apple was $38.0^{\circ} \mathrm{C}$, and near the equator it was $36.9^{\circ} \mathrm{C}$. The KT pyrometer provided a $15-$ min spot value of $36.7^{\circ} \mathrm{C}$ for the averaging period 12:30-12:45 CET. b Experimental setup for measuring the apple temperature with resistance thermometers and infrared radiation pyrometers (KT 19, VarioCam, see Measurements)

Model simulations of Smart and Sinclair (1976) revealed that, under identical environmental conditions, larger fruits become much warmer than smaller ones. For example, the hot-spot skin temperature of a fruit of $9 \mathrm{~cm}$ diameter is approx. $8^{\circ} \mathrm{C}$ above that of a fruit of $3 \mathrm{~cm}$ diameter when $u_{a}=1 \mathrm{~m} \mathrm{~s}^{-1}$ and $S_{\downarrow}=1050 \mathrm{~W} \mathrm{~m}^{-2}$ (see their Fig. 2, $\alpha_{f}=0.22$ ). Focusing on equilibrium volume temperatures of spheres, our model yields a similar temperature difference of $6^{\circ} \mathrm{C}$ for $u_{a}=1 \mathrm{~m} \mathrm{~s}^{-1}, S_{\downarrow}=1000 \mathrm{~W} \mathrm{~m}^{-2}$ and $\alpha_{f}=0.25$ for fruit diameters of 9 and $3 \mathrm{~cm}$ (Fig. 3b). In terms of radiant energy exposure, larger spheres may absorb more radiation energy than smaller ones, and are less prone to convective heat loss because of the greater aerodynamic resistance of larger spheres.

Note that our model theory is kept as simple as possible and confines the calculation of fruit temperatures to the upand downward facing hemispheres of apples. Knowledge of the fruit-volume temperature seems to be sufficient for sunburn prediction because skin discoloration (as the typical sunburn symptom) usually extends over a large area on the sun-exposed apple surface (see Figs. 2 and $5 \mathrm{~b}$ in Schrader et al. 2001) and there is light penetration into the subjacent cell layers (Hother et al. 1995) with residual light absorption at the fruit center (Blanke 1989).

Miscalculations may occur during fair summer days in daylight and with low wind speeds (e.g. less than $1.5 \mathrm{~m} \mathrm{~s}^{-1}$ ). These conditions may lead to dubious short-term temperature peaks due to high $r_{h}$ values arising from underestimated forced convection. Trials to alleviate this behavior by reinforcing turbulence intensity via superposition of natural convection were not successful (tests not shown). Therefore, an upper $r_{h}$ threshold was defined by bounding $R e$ (Eq. 6) via $\operatorname{Re}=\operatorname{Re}\left(u_{a, c r}\right)$ if $u_{a}$ falls below the critical value $u_{a, c r}=1.5 \mathrm{~m} \mathrm{~s}^{-1}$ as long as $S_{\downarrow}>125 \mathrm{~W} \mathrm{~m}^{-2}$. Similar erroneous model behavior is found by McCaskill et al. (2016; see spikes in their Fig. 1).
We emphasize that the mean absolute error of $1.7^{\circ} \mathrm{C}$ between daily maxima of measured skin and modeled upper fruit temperature is of the same order of magnitude as the skin temperature difference between the anti-solar point and sunlit fruit equator. Around noon, a difference of approx. $1.5 \mathrm{~K}$ occurs between the poleward and near-equator regions plotted as circles on the south-facing side of the apple (Fig. 7a). The lower circle near the apple's equator represents the approximate position of the measuring patch of the KT19 sensor, while the upper one near the apple's stalk (north pole) represents the region where the maximum skin temperature can be expected around noon. It should be kept in mind that the position of the KT's measuring spot is focused on the near-equator region of the apple during the whole measuring period so that the KT's locally sensed skin temperature is only a proxy of the hottest area found somewhere further up on the sun-exposed side of the fruit.

One of our model simplifications is based on the assumption of a permanently dry fruit surface meaning that evaporative cooling of rain- or dew-induced surface wetness is disregarded. In addition, transpirational fruit-water losses are neglected because the aerodynamic resistance, which affects the water vapor transfer in its pathway between the bottom and the top of the apple's boundary layer (about $1 \mathrm{~mm}$ thick), is very high, e.g. $5 \times 10^{5}$ and $7 \times 10^{5} \mathrm{~s} \mathrm{~m}^{-1}$ for Jonathan and Granny Smith apples with diameters of $d_{f}=6 \mathrm{~cm}$, respectively (see Tab. 2 in Nobel 1975). These figures are roughly in line with those found by Jones and Higgs (1982) who showed that the aerodynamic resistance for water-vapor transfer at the skin was in the order of $10^{4}-10^{5} \mathrm{~s} \mathrm{~m}^{-1}$ and the maximum rate of fruit water loss was $0.2 \mathrm{~g} \mathrm{day}^{-1}$. Note that focusing on detached apples also ignores water supply via sap flow and corresponding cooling.

However, the main constraint of our theoretical assumptions is the restriction to one dimension, i.e. the fruit diameter is the only geometrical and scale factor, with the 
result that spatial modeling focusses on hemispherical volume averages. For this reason we have to accept a larger $R M S E$ of $2.3^{\circ} \mathrm{C}$ compared to $0.8^{\circ} \mathrm{C}$ obtained by Saudreau et al. (2007) using a highly resolved 3-D model. Despite the reduced predictive accuracy, our results are in line with previous studies of Thorpe (1974) and Smart and Sinclair (1976). Nevertheless, testing and recalibration of the model is advised when it is applied to sphere diameters which differ significantly from the model-default value $(7 \mathrm{~cm})$ or when it is used for apples grown in extreme climates.

\section{Conclusions}

At DWD's Agrometeorological Research Centre in Braunschweig, northern Germany, apple temperatures were measured on fair summer and fall days as a marker for sunburn disorder. On average, on the 111 selected warm and sunny days, the excessive surface heating found on the south-facing side was about $7{ }^{\circ} \mathrm{C}$ above the daily maximum air temperature. However, sunburn-specific skin temperatures of more than $40^{\circ} \mathrm{C}$ were rarely achieved, meaning that sunburn is still an uncommon phenomenon in Germany. Maximum daily apple core temperatures were, on average, $4{ }^{\circ} \mathrm{C}$ warmer than the maximum value of ambient air, and were less prone to fluctuating atmospheric disturbances.

Based on energy balance principles, a simple model was developed to calculate the diurnal temperature of the skyand ground-facing hemispheres of an apple. The model was built for operational use with data supplied from DWD's measuring network stations and numerical weather-forecast models. The calculation scheme is a compromise between empirical one-parameter to multi-parameter approaches (Holmes et al. 2009 (cited by Lolicato 2011); Wagner and Böttcher 2010; Schrader 2010) and complex 3D-modeling based on a high number of grid points (Saudreau et al. 2007).

Focusing on fruit growers' needs, daily temperature maxima of the modeled sky-facing hemisphere are compared with radiation temperatures of a measuring patch on the sunlit southern side. Model performance measures yield a mean absolute error of $1.7^{\circ} \mathrm{C}$ and a root mean square error of $2.3^{\circ} \mathrm{C}$, while the coefficient of determination and the coefficient of efficiency were approx. 0.5. Comparison between the daily maxima of total sphere temperatures and apple core temperatures provided better performance measures (see Table 1). However, it remains unresolved whether stable total fruit temperatures are a better (more customer-oriented) alternative than the more variable skyfacing temperatures for initiating fruit-protection measures against sunburn. Note that McCaskill et al. (2016) had to introduce a calibration factor to adjust the theoretical outcomes of the Smart and Sinclair (1976) model to their own experimental data. In this way, a model error of more than $6^{\circ} \mathrm{C}$ on the sun-exposed side of apples could be eliminated.

The main result is that the simple net-radiometer-like two-half concept of the model is sufficient to provide reasonable estimates of fruit temperatures. As our model can be easily adjusted to deviating in-situ fruit-temperature measurements via pre-set control parameters (such as $\alpha_{f}$ ), fruit growers can benefit from the model forecasts. For example, preventive sun-protection measures can be initiated as soon as critical sky-facing fruit temperatures of $40^{\circ} \mathrm{C}$ (used as a benchmark) are exceeded. It requires time to take measures against photo-thermal stresses, such as overtree sprinkling, over-tree shade netting, spraying of kaolin and soil-irrigation measures, meaning that forecasting of fruit temperatures is a first and essential step for orchardmanagers if they wish to be prepared. For an excellent overview summarizing all these sunburn risk-reduction options and best orchard management practices, see Lolicato (2011) and Racskó and Schrader (2012).

Besides the objective of issuing early warnings, a further interesting application of our model will be estimation of the impact of climate change on the severity of apple sunburn. Yet, in contrast to other countries such as Australia (see Webb et al. 2017), this topic is still omitted from climate projections in Germany, although DWD's data records of air temperature and global radiation have already revealed a positive trend over recent decades. Moreover, heat waves are projected to become more frequent in the future so that the economic significance of sunburn injury will probably increase. Based on the model projections, decision makers might be able to develop suitable long-term adaptation strategies to reduce fruit vulnerability by breeding more stress-tolerant apple varieties, or introducing new cultivation methods (Hanke 2017). Furthermore, it will be possible to identify alternative growing areas which will be agro-climatologically more favorable in the future.

Acknowledgements The author thanks Dr. M. Blanke (University of Bonn, Germany) for providing Fig. 1 as well as for his valuable comments that helped to improve the manuscript.

Special appreciation also goes to Dr. M. Herbst (DWD, Braunschweig) for his constructive suggestions.

Funding Open Access funding enabled and organized by Projekt DEAL.

Conflict of interest K.-P. Wittich declares that he has no competing interests.

Open Access This article is licensed under a Creative Commons Attribution 4.0 International License, which permits use, sharing, adaptation, distribution and reproduction in any medium or format, as long as you give appropriate credit to the original author(s) and the source, provide a link to the Creative Commons licence, and indicate if changes were made. The images or other third party material in this article are included in the article's Creative Commons licence, unless indicated otherwise in a credit line to the material. If material is not included 
in the article's Creative Commons licence and your intended use is not permitted by statutory regulation or exceeds the permitted use, you will need to obtain permission directly from the copyright holder. To view a copy of this licence, visit http://creativecommons.org/licenses/by/4. $0 \%$.

\section{References}

Blanke M (1989) Wieviel Licht nimmt eine Apfelfrucht auf? (Light absorption of developing apple fruit). Erwerbsobstbau 31:157-161

Blanke M, Lenz F (1985) Spaltöffnungen, Fruchtoberfläche und Transpiration wachsender Apfelfrüchte der Sorte 'Golden Delicious'. Erwerbsobstbau 27:139-143

Brooks C, Fisher DF (1926) Some high-temperature effects in apples: contrasts in the two sides of an apple. J Agric Res 32:1-16

Butler DR (1976) Estimation of the transpiration rate in an apple orchard from net radiation and vapour pressure deficit measurements. Agric Meteorol 16:277-289

Darbyshire R, McClymont L, Goodwin I (2015) Sun damage risk of Royal Gala apple fruit-growing districts in Australia. N Z J Crop Hortic Sci 43:222-232

Donsì G, Ferrari G, Nigro R (1996) Experimental determination of thermal conductivity of apple and potato at different moisture contents. J Food Eng 30:263-268

Evans RG (2004) Energy balance of apples under evaporative cooling. Trans ASAE 47:1029-1037

Green SR, McNaughton KG (1997) Modelling effective stomatal resistance for calculating transpiration from an apple tree. Agric For Meteorol 83:1-26

Häckel H (1973) Über die Wärmeleitfähigkeit von Fruchtfleisch. Gartenbauwissenschaft 38:139-150

Hanke M-V (2017) Klimawandel - Ausrichtung der Züchtung bei Obst. J Kulturpflanz 69:51-52

Hellebrand HJ, Beuche H, Linke M, Herold B, Geyer M (2001) Chances and shortcomings of thermal imaging in the evaluation of horticultural products. http://www2.atb-potsdam.de/hauptseitedeutsch/Institut/Abteilungen/abt2/mitarbeiter/jhellebrand/jhelle brand/Publikat/PMA2001.pdf. Accessed 13 July 2020

Holmes R, Crisera M, Brown G (2009) Harvest and post harvest options for heat affected apples and pears. Aust Fruitgrow 2:8-10

Hother K, Herold B, Geyer M (1995) Grenzen und Erkennung von Qualitätsfehlern im Apfelgewebe bei Messung der spektralen Reflexion. Gartenbauwissenschaft 60:162-166

Jones HG, Higgs KH (1982) Surface conductance and water balance of developing apple (Malus pumila Mill.) fruits. J Exp Bot 33:67-77

Kobel F (1931) Lehrbuch des Obstbaus. Springer, Berlin

Landsberg JJ, Powell DBB, Butler DR (1973) Microclimate in an apple orchard. J Appl Ecol 10:881-896

Lebe R, Schulte E (2008) Sonnenbrandschäden an Apfelfrüchten in der Saison 2007. Obstbau 33:309-312

Legates DR, McCabe GJ (1999) Evaluating the use of "goodness-offit" measures in hydrologic and hydroclimatic model validation. Water Resour Res 35:233-241

Li L, Peters T, Zhang Q, Zhang J, Huang D (2014) Modeling apple surface temperature dynamics based on weather data. Sensors 14:20217-20234

Lisowa H, Wujec M, Lis T (2002) Influence of temperature and variety on the thermal properties of apples. Int Agrophys 16:43-52

Lolicato S (2011) Sun protection for fruit. A practical manual for preventing sunburn on fruit. Farm Services Victoria, Department of Primary Industries, Victoria, Australia

Makeredza B (2011) Studies towards understanding sunburn in apple. Master thesis, Dept. of Horticultural Science, Stellenbosch University, South Africa

McAdams WH (1954) Heat transmission. McGraw-Hill, New York
McCaskill MR, McClymont L, Goodwin I, Green S, Partington DL (2016) How hail netting reduces apple fruit surface temperature: a microclimate and modelling study. Agric For Meteorol 226/227:148-160

Monteith JL, Unsworth MH (2013) Principles of environmental physics, 4th edn. Elsevier, Amsterdam

Nash JE, Sutcliffe JV (1970) River flow forecasting through conceptual models. Part I-A discussion of principles. J Hydrol 10:282-290

Nobel PS (1975) Effective thickness and resistance of the air boundary layer adjacent to spherical plant parts. J Exp Bot 26:120-130

Racskó J, Schrader LE (2012) Sunburn of apple fruit: Historical background, recent advances and future perspectives. CRC Crit Rev Plant Sci 31:455-504

Saudreau M, Marquier A, Adam B, Monney P, Sinoquet H (2009) Experimental study of fruit temperature dynamics within apple tree crowns. Agric For Meteorol 149:362-372

Saudreau M, Sinoquet H, Santin O, Marquier A, Adam B, Longuenesse J-J, Guilioni L, Chelle M (2007) A 3D model for simulating the spatial and temporal distribution of temperature within ellipsoidal fruit. Agric For Meteorol 147:1-15

Schrader L (2010) Interactive sunburn model. Tree Fruit Research and Extension Center, Washington State University, Wenatchee

Schrader L, Sun J, Felicetty D, Seo J-H, Jedlow L, Zhang J (2003a) Stress-induced disorders: Effects on apple fruit quality. In: Washington Tree Fruit Postharvest Conference Wenatchee, WA, 2-3 December 2003

Schrader L, Zhang J, Sun J (2003b) Environmental stresses that cause sunburn on apple. Acta Hortic 618:397-405

Schrader LE, Zhang J, Duplaga WK (2001) Two types of sunburn in apple caused by high fruit surface (peel) temperature. Plant Health Prog. https://doi.org/10.1094/PHP-2001-1004-01-RS

Smart RE, Sinclair TR (1976) Solar heating of grape berries and other spherical fruits. Agric Meteorol 17:241-259

Steffens M (2008) Einsatz der klimatisierenden Beregnung zum Schutz vor Sonnenbrand. Mitt Obstbauversuchsringes Alten Landes 63:353-354

Steffens M (2013) Rückblick auf die Sonnenbrandsituationen in 2012 Bericht aus Sicht der Beratung. Mitt Obstbauversuchsringes Alten Landes 68:119-121

Sweat VE (1974) Experimental values of thermal conductivity of selected fruits and vegetables. J Food Science 39:1080-1083

Thorpe MR (1974) Radiant heating of apples. J Appl Ecol 11:755-760

Tscheuschner H-D (ed) (2004) Grundzüge der Lebensmitteltechnik. Behr's Verlag, Hamburg

VDI (Verein Deutscher Ingenieure) (2006) VDI Wärmeatlas - Berechnungsblätter für den Wärmeübergang, 10th edn. Springer, Berlin

Wagner J, Böttcher F (2010) Sonnenbrand am Apfel. Schweiz Z Obst Weinbau 146(11):10-12

Webb L, Darbyshire R, Erwin T, Goodwin I (2017) A robust impact assessment that informs actionable climate change adaptation: future sunburn browning risk in apple. Int $\mathrm{J}$ Biometeorol 61:891-901

Wiebusch J-H (2019) Sonnenbrand an Äpfeln. Mitt Obstbauversuchsringes Alten Landes 74:157-161

Willmott CJ, Matsuura K (2005) Advantages of the mean absolute error (MAE) over the root mean square error (RMSE) in assessing average model performance. Clim Res 30:79-82

WMO (2014) Guide to meteorological instruments and methods of observation. https://www.wmo.int/pages/prog/www/IMOP/CIMOGuide.html. Accessed 13 July 2020 (WMO-No. 8) 